
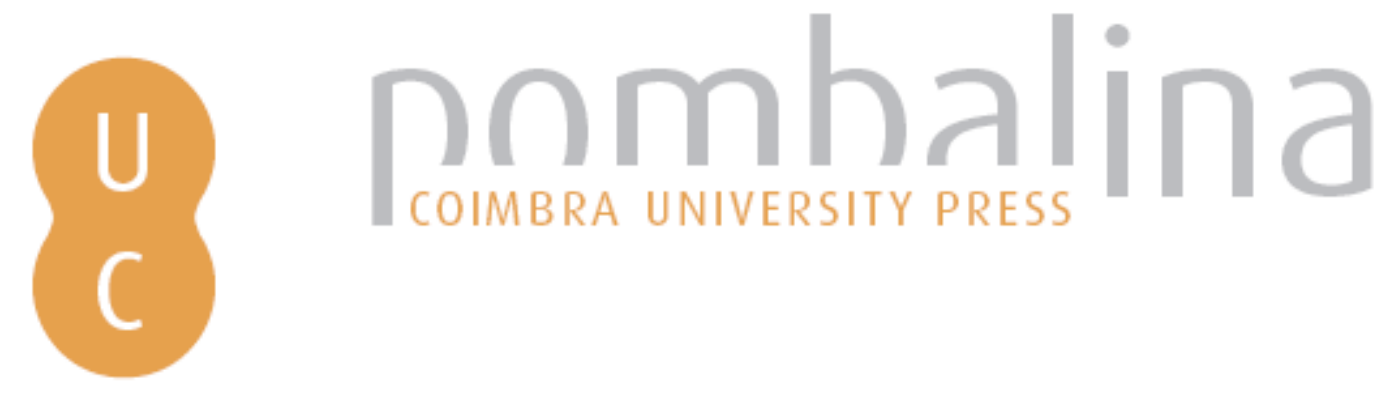

\title{
Los Libros de la naturaleza que viajaron a Puebla Segunda mitad del siglo XIX
}

Autor(es): Jaramillo, Ana María Dolores Huerta

Publicado por: Imprensa da Universidade de Coimbra

URL

persistente: URI:http://hdl.handle.net/10316.2/32376

DOI: $\quad$ DOI:http://dx.doi.org/10.14195/978-989-26-0469-5_6

Accessed : $\quad$ 26-Apr-2023 04:42:45

A navegação consulta e descarregamento dos títulos inseridos nas Bibliotecas Digitais UC Digitalis, UC Pombalina e UC Impactum, pressupõem a aceitação plena e sem reservas dos Termos e Condições de Uso destas Bibliotecas Digitais, disponíveis em https://digitalis.uc.pt/pt-pt/termos.

Conforme exposto nos referidos Termos e Condições de Uso, o descarregamento de títulos de acesso restrito requer uma licença válida de autorização devendo o utilizador aceder ao(s) documento(s) a partir de um endereço de IP da instituição detentora da supramencionada licença.

Ao utilizador é apenas permitido o descarregamento para uso pessoal, pelo que o emprego do(s) título(s) descarregado(s) para outro fim, designadamente comercial, carece de autorização do respetivo autor ou editor da obra.

Na medida em que todas as obras da UC Digitalis se encontram protegidas pelo Código do Direito de Autor e Direitos Conexos e demais legislação aplicável, toda a cópia, parcial ou total, deste documento, nos casos em que é legalmente admitida, deverá conter ou fazer-se acompanhar por este aviso. 
Ana Leunar Pereira João Rui Pita

[ Coordenaçä̃ ]
Rotas da Natureza

Cientistas

Viagens

Expedifgũes

Instituip̧ües

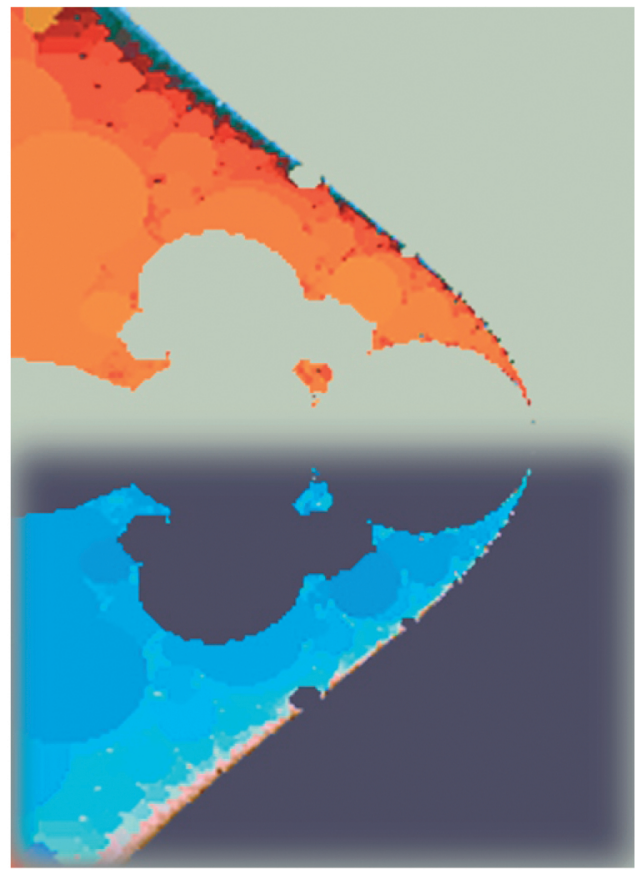




\section{Coordenaçáo Científica da Colecção Ciências e Culturas}

João Rui Pita e Ana Leonor Pereira

Os originais enviados são sujeitos a apreciação científica por referees

\section{Coordenação Editorial}

Maria João Padez Ferreira de Castro

\section{Edição}

Imprensa da Universidade de Coimbra

Email:impresauc@ci.uc.pt

URL: http://www.imp.uc.pt • Normas de publicação de colecçôes

\section{Design}

António Barros

Pré-Impressáo

António Resende

Imprensa da Universidade de Coimbra

\section{Capa}

António Barros, com imagem de E. M. de Melo e Castro, 2003 [Fractal original gerado no Fractint com tratamento no Photoshop 7.0]; Cortesia: António Barros

Impressão e Acabamento

SerSilito • Maia

\section{ISBN}

978-989-8074-12-6

\section{Depósito Legal}

Obra publicada com a colaboraçáo de:
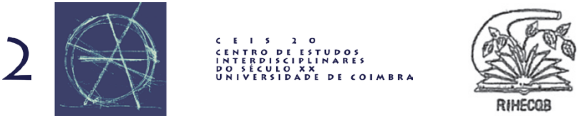

Obra publicada com o apoio de:

FCT Fundação para a Ciência e a Tecnologia

MINISTÉRIO DA CIÊNCIA, TECNOLOGIA E ENSINO SUPERTOR Portug

Programa Operacional Ciência, Tecnologia, Inovação do Quadro Comunitário de Apoio III
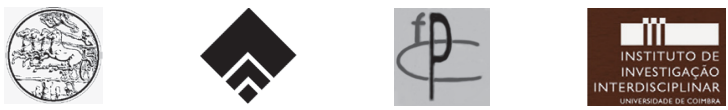

\section{Baxter}

(c) 2006, Imprensa da Universidade de Coimbra 
João Rui Pita

Ana Leonar Pereira

(Courdenação)

Rotas da Natureza

Cientistas

Viagens

Expediçũes

Instituiç̃̃es

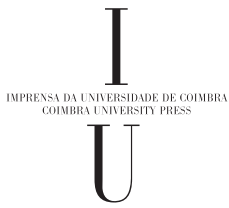

- colmbra 2006 
(Página deixada propositadamente em branco) 


\author{
Ana María Dolores Huerta Jaramillo \\ Area de Historia. Instituto de Ciencias Sociales y Humanidades. \\ Benemérita Universidad Autónoma de Puebla, México
}

\title{
Los Libros de la naturaleza que Viajaron a Puebla SEgUNDA MITAD DEL SIGLO XIX
}

Viajes y colecciones constituyen los dos polos de la historia natural. Libros que viajaron de un lugar a otro, como lo hicieron las diferentes especies vegetales, animales y minerales que se clasificaron para la construcción de un nuevo orden científico, que sustituyó o se desarrolló a la par del orden religioso. Especies de todo tipo transitaron por diferentes rutas que ayudaron a encontrar los parentescos con las especies locales de cada continente, la herramienta principal para ese reconocimiento fueron los textos impresos que construyeron imágenes e imaginarios.

En 1875 se instaló en la Escuela de Medicina de Puebla, el gabinete de Historia Natural, ${ }^{1}$ un albergue de la naturaleza. En el se integraron diferentes colecciones anatómicas humanas, especies animales, minerales y un herbario. ${ }^{2}$ Además de instrumentos de laboratorio el Gabinete contó con una extensa biblioteca con textos procedentes de Europa, manuales especializados, tratados sobre especies, diccionarios, diversas historia naturales, información que respaldaba todas las clasificaciones y cuyo aprovechamiento se difundía a través de la enseñanza. Con el tiempo algunos de esos libros se integraron a los anaqueles de la Biblioteca Central José María Lafragua de la Universidad Autónoma de Puebla, y se nos presentan como una oportunidad para realizar una revisión acerca de la producción historiográfica sobre la naturaleza que llegó a tierras americanas durante el siglo XIX.

Los insectos a una Enciclopedia

De 1875 data la Enciclopedia de Historia Natural o Tratado completo de esta Ciencia, cuyo autor se nombra como Doctor Chenú, cirujano mayor en el Hospital Militar de

\footnotetext{
${ }^{1}$ Archivo Histórico Escuela de Medicina. Biblioteca Central José María Lafragua. «Inventario de los muebles, utensilios, que existen en el Gabinete de Historia Natural. 1907.» Manuscrito. 40 hojas

2820 especies de aves, de las cuales la mayor parte eran de procedencia extranjera, 85 especies de mamíferos de distintas clases, 81 reptiles, 56 tipos de peces, 10 ejemplares de felinos, 17 ejemplares de roedores, 4 primates y 2 marsupiales.
} 
Val-de-Grass y profesor de Historia Natural. ${ }^{3}$ En ella se incluyen los trabajos de «los naturalistas más eminentes de todos los países y de todas las épocas» como Buffon, Daubenton, Lacepede, Georges y F. Cuvier, Geoffroy Saint-Hilaire, Latreille, Jussieu, Brongniart. El tomo del que nos ocuparemos es el correspondiente a los anélidos, trabajo integrado con la colaboración de Desmarest del Museo de Historia Natural y Secretario de la Sociedad Entomológica de Francia. Este volumen contiene una Tabla alfabética de los nombres vulgares y científicos de todos los temas descritos y figuras. ${ }^{4}$ La idea del autor es que gracias a las viñetas y dibujos que se incluyen en el texto, es posible conocer suficientemente las especies verdaderamente útiles, y los grupos genéricos admitidos por los autores, remitiendo a obras especiales que podrían completar las nociones que se dan. La justificación principal de producir un texto de estas características se debió a la necesidad que se tenía de conocer los anélidos útiles y diferenciarlos de los que se consideraban como enemigos del hombre. Como anélidos útiles se incluyeron a: la abeja que produce miel y cera; la cochinilla que se había aprovechado durante mucho tiempo y que constituye en sí misma un bello color tintóreo; ciertos himenópteros como el denominado blastófago ${ }^{5}$ que producen el fenómeno de la fecundación necesaria para lograr la maduración de lo higos en ciertos países; los insectos del género cynips, que producen en contacto con el roble la tinta o tinte conocido como negro de Gales; las hormigas, interesantes por ellas mismas, que neutralizan la acción desagradable de los pulgones sobre la mayoría de los arbolillos; la sanguijuela, que era ventajosamente empleada en la medicina. Entre los anélidos dañinos que se debían conocer para impedir sus estragos se señalaba a las cucarachas que maltratan las provisiones; los grillos, perjuicio de los agricultores; toda clase de chapulines y langostas que arriban en bandas inconmensurables, la pulga de la rata que produce la peste; las termitas que roen los bosques; las avispas y abejorros que producen crueles piquetes y heridas; las avispas de los pinos que devastan esta foresta y que son célebres por las perforaciones que ocasionan en los troncos; los piojos, las arañas, la tarántula, los escorpiones, y los ácaros que propagan la sarna. Los grupos de que se encontraban presentes en el Gabinetes de Historia Natural de Puebla por su clasificación eran: los miriápodos ${ }^{6}$,

\footnotetext{
${ }^{3}$ Dr. Chenú. Encyclopédie D'Histoire Naturelle ou Traité complet de cette Science. D'apres les Travaux des Naturalistes les plus eminents de tous les pays et de toutes les Epoques, Buffon, Daubenton, Lacepede, G. Cuvier, F. Cuvier, Geoffroy Saint-Hilaire, Latreille, de Jussieu, Brongniart...etc... Annelés. París, Maresq et Compagnie/Gustave Havard, 1875

${ }^{4}$ Encyclopédie D'Histoire Naturelle. Table Alphabetique des nomes vulgaires et scientifiques de tous les sujets décrits et figurés dans cette encyclopédie. Annelés. París, Libraire de Firmin-Didot et $\mathrm{C}^{\mathrm{ie}}$, Imprimeurs de L'institut, 1875.

${ }^{5}$ Introduciéndose en los higos efectúa la polinización y asegura la madurez de estas variedades que, sin esta práctica dejan caer los frutos prematuramente.

${ }^{6}$ Grupo de artrópodos mandibulados y antenados, de respiración traqueal, caracterizados por presentar numerosos segmentos. Enciclopedia Textual Permanente, Salvat Editores, 1999.
} 
arácnidos $^{7}, \operatorname{coleópteros}^{8}$ (insectos de 4 alas), ortópteros ${ }^{9}$ (grillos), himenópteros ${ }^{10}$ (abejas), lepidópteros ${ }^{11}$ (mariposas).

\section{La historia natural en una galería}

Una Galería de Historia Natural publicada en 1885 se presenta como «sacada de las obras completas de Buffon ${ }^{12}$ y arreglada al castellano por García-Ramón. Se trata de una preciosa edición «adornada con 32 grabados en acero dibujados por Travíes y

\footnotetext{
${ }^{7}$ Clase de artrópodos, generalmente terrestres, que presentan el cuerpo seccionado en dos partes: un cefalotórax o prosoma, provisto de seis pares de apéndices, y el abdomen u opistosoma, ápodo. Ibidem.

${ }^{8}$ Orden de insectos caracterizados por la presencia de un primer par de alas queratinizadas o élitros que sirven de estuche a un segundo par de alas membranosas que les sirven para volar. Sin embargo, ambos pares de alas faltan o están atrofiadas en muchos casos. El desarrollo es holometábolo, con larvas ápodas y ninfas móviles. El aparato bucal es generalmente masticador. Es uno de los órdenes más extensos y variados del reino animal, conociéndose en la actualidad no menos de 300.000 especies que han poblado toda clase de hábitats. El grado de especialización es asimismo elevadísimo; es uno de los grupos animales mejor adaptados. Muchas especies son altamente perjudiciales para la agricultura. Suelen dividirse en dos grandes subórdenes: adéfagos y polífagos. Ibidem.
}

${ }^{9}$ Orden de insectos heterometábolos que comprende los llamados saltamontes, langostas y grillos. Tiene el aparato bucal masticador, dos pares de alas, el primero coriáceo, y las partes posteriores muy grandes y adaptadas al salto. Algunas especies son ápteras o con las alas reducidas. Es característica del grupo la presencia de órganos estridulantes. Comprende más de 15.000 especies repartidas por todo el mundo. Ibidem.

${ }^{10}$ Orden de insectos pterigotas holometábolos. Su tamaño varía entre 0,1 y $50 \mathrm{~mm}$. El aparato bucal es masticador o lamedor. Tienen cuatro alas membranosas, unidas durante el vuelo por unos ganchos. Las hembras presentan un oviscapto que en algunas especies se convierte en un aguijón venenoso. La partenogénesis es muy frecuente; por lo general los huevos no fecundados producen machos. Las formas más evolucionadas del orden presentan muchos casos de especies altamente sociales (hormigas, abejas, avispas), con un acusado polimorfismo: hembras, machos y obreras. Comprende unas 280.000 especies, casi todas terrestres. Suelen dividirse en dos subórdenes: sínfitos, con las piezas bucales masticadoras y abdomen no pedunculado, y apócritos, con el abdomen pedunculado. Ibídem.

${ }^{11}$ Orden de insectos holometábolos, con 4 alas grandes membranosas recubiertas de pequeñas escamas y con un aparato bucal chupador típico llamado espiritrompa, formado por las maxilas. Sus larvas (orugas) poseen aparato bucal masticador, tres patas dorsales y, a veces, falsas patas abdominales. La crisálida suele ser inmóvil y muchas veces está protegida por un capullo. Es bastante frecuente el dimorfismo sexual; la coloración es muy variable y generalmente muy vistosa. Ojos compuestos bien desarrollados y antenas de conformación y longitud variables. Las larvas son fitófagas, y muchas veces perjudiciales para la agricultura; los adultos chupan el néctar y el polen de las flores. Todos son terrestres, aunque algunas larvas pueden ser dulceacuícolas. Ibidem.

${ }^{12}$ Buffon, Georges-Louis Leclerc, conde de (1707-1788). Naturalista francés. En 1739 fue nombrado director del jardín botánico del rey y de su museo adjunto. Al encargársele la elaboración de un catálogo del museo, se dedicó desde 1749 a dirigir y redactar en gran parte una inmensa Historia natural de 36 volúmenes, a los que tras su muerte se añadieron 8 más. En ella se tratan principalmente los animales, pero también se dedican volúmenes al ser humano, los vegetales, los minerales y la historia de la Tierra y el Sistema Solar. De estilo vivaz y colorista, la Historia natural tuvo un gran éxito y contribuyó a la difusión de las incipientes ideas evolucionistas sobre el origen de la Tierra y los seres vivos. Ibídem. 
Enrique Gobin e iluminados por los mejores artistas». ${ }^{13}$ La designación de Galería es atinada pues las noticias sobre los ejemplares zoológicos son acompañadas de bellísimas ilustraciones de página completa con pespuntes para ser desprendidas y enmarcadas y aprovecharse como material didáctico. Los autores a los que remite constantemente a lo largo de la obra son Cuvier, ${ }^{14}$ Flourens y Plinio ${ }^{15}$. Lo primero que encontramos después de la portada es un estudio introductorio sobre la vida y obra de Bufón donde se resalta su Historia Natural de los Animales y que se califica como «su verdadero monumento, el que siempre subsistirá y le merecerá la admiración, el respeto y la gratitud de las generaciones venideras». ${ }^{16}$ En este texto existen dos tipos de imágenes, las pictóricas y las literarias. En cuanto a las segundas se trata de un traslado de representaciones imaginarias de atributos y carencias de las diversas especies, ideas que se han construido a través de la lectura de textos de Historia Natural de diferente procedencia y autoría. En particular llama la atención la forma en que se describe la interacción entre los habitantes y los animales procedentes de diferentes meridianos, en particular me referiré sólo a algunos ejemplos y contrastes entre lo americano, lo mexicano y lo europeo. Cuando se refiere al cocodrilo afirma que ciertas especies que Plinio no conoció y que se encontraban en algunos parajes de América, "como todos los grandes animales de esas regiones nuevas en las que la humedad es superior al calor, tiene menos valor y fuerza que los animales que los representan en los países

${ }^{13}$ García-Ramón. Galería de Historia Natural. Sacada de las obras completas de Bufón y arreglada al castellano por... Edición adornada con 32 grabados en acero dibujados por Travíes y Enrique Gobin e iluminados por los mejores artistas. París, Librería Española de Garnier Hermanos, 1885.

${ }^{14}$ Cuvier, Georges (1769-1832). Naturalista francés. Cursó estudios en Alemania. En 1795 pasó a formar parte del equipo científico del Jardin des Plantes de París e ingresó en la Academia de Ciencias. En 1799 fue designado como sucesor de Daubenton en la cátedra de historia natural del Collège de France. Gozó del favor de Napoleón, Luis XVIII - que lo nombró barón - y Luis Felipe; en 1818 fue elegido miembro de la Academia Francesa. Inspirándose en Aristóteles, emprendió la tarea de establecer las leyes de una anatomía funcional, y puede considerársele como el fundador de la anatomía comparada. Sus investigaciones abarcan todo el reino animal, en el que distingue cuatro grandes tipos de organización: vertebrados, moluscos, articulados y radiados. Formuló el principio de la correlación de los órganos, según el cual éstos no están simplemente yuxtapuestos, sino que actúan los unos sobre los otros para realizar una función común. Puede considerársele como uno de los fundadores de la paleontología; describió y estudió numerosas especies fósiles, principalmente vertebrados. Sostenía, sin embargo, que estas especies no tenían relación con las actuales, al no poder demostrarse la existencia de formas intermedias entre unas y otras; influido por sus ideas religiosas, se mostró partidario de una concepción fijista: las especies no podían derivar las unas de las otras por cambios graduales. Se opuso en este terreno a las teorías transformistas de Lamarck y Geoffroy de Saint-Hilaire, con quienes sostuvo polémicas de gran interés. Obras principales: Leçons d'anatomie comparée (1800-05), Le règne animal distribué d'après son organisation (1817), Histoire naturelle des poissons (1828), etc. Enciclopedia Textual, op.cit.

${ }^{15}$ Plinio el Viejo, Cayo Plinio Cecilio Segundo, llamado (23 ó 24-79). Escritor romano. Tío de Plinio el Joven, éste lo cita como autor de obras históricas y de carácter retórico y gramatical. De él sólo se conserva una Historia Natural (Naturalis historia XXXVII libri), compilación del saber antiguo con índice de materias y enumeración de fuentes aprovechadas. Son particularmente valiosas las noticias que aporta para la historia del arte y para los estudios geográficos. El estilo es seco y conciso y de escaso valor literario. Una epístola de su sobrino para Tácito refiere las circunstancias de su muerte durante la famosa erupción del Vesubio. Ibidem.

${ }^{16}$ García Ramón. Op. cit., p. VIII. 
secos del antiguo continente». ${ }^{17}$ En el caso de la Boa constrictor ${ }^{18}$ señala que como todo lo que produce terror y la admiración parece tener gran superioridad sobre los otros seres «causa en los cerebros poco ilustrados la idea de un agente sobrenatural». A ello se atribuía que los antiguos habitantes de México consideraban a la Boa con religioso temor, pensaban que una masa tan considerable que ejecutaba movimientos rápidos no podía ser movida sino por un soplo divino, o debido a que era ministro de la «omnipotencia celeste», convirtiéndose en objeto de culto. «La apellidaron emperador para designar la preeminencia de sus cualidades». ${ }^{19}$ Acerca de la víbora de cascabel, García-Ramón nos informa que los mexicanos la designan como escacoatl, que significa el viento. Lo considera «funesto reptil» que habita casi todas las regiones del nuevo mundo, desde la tierra de Magallanes ${ }^{20}$ hasta el lago Champlain, hacia el cuadragésimo quinto grado de latitud septentrional. La víbora de cascabel reinaba en esas vastas regiones en las que ningún animal se atrevía a atacarlas y «los antiguos americanos no mataban retenidos por supersticiosos temor; pero animados por los europeos en breve han tratado de libertarse de esa terrible especie...". ${ }^{21}$

La valoración cambia cuando se trata de informar acerca de la Llama, variedad doméstica del guanaco originaria del Perú, utilizada como animal de carga. Apoyándose en noticias de Gregorio de Bolivar, el autor de la Galeria informa que desde el Perú, su verdadera patria, las llamas eran conducidas a otras provincias, como a Nueva España, más por curiosidad que por utilidad. Mientras que en toda la extensión del Perú, desde Potosí2 hasta Caracas, estos animales eran muy numerosos, así como necesarios, formando «la única riqueza de los Indios» y contribuyendo mucho a la de los españoles. Su carne se describe como buena para comer, su pelo como una lana fina de un uso excelente, y durante toda su vida sirven para transportar los productos del país. Su carga ordinaria era de 150 libras y los animales más fuertes llevaban hasta 250, haciendo viajes bastante largos en lugares escabrosos para otra clase de animales. $\mathrm{Su}$ andar lento les permite recorrer cuatro o cinco leguas al día; «los ocupan mucho para el transporte de los minerales que se sacan de Potosí». 23 Atrás se quedaron los bestiarios medievales, ${ }^{24}$ las especies animales habían sido desprovistas de su asociación

${ }^{17}$ Idem. p. 293

${ }^{18}$ La boa constrictora (Boa constrictor o Constrictor constrictor) captura sus presas lanzándose desde los árboles y las tritura enroscándose sobre ellas. Se encuentra en América centromeridional.

${ }^{19}$ García-Ramón. Op. cit. P. 369

${ }^{20}$ Magallanes. Estrecho del S. de América, que comunica el Atlántico con el Pacífico y separa la Tierra del Fuego del continente; $600 \mathrm{kms}$. de longitud y 33 de anchura media. Descubierto por F. de Magallanes en 1520. Enciclopedia Textual, op. cit.

${ }^{21}$ García-Ramón. Op. cit. p. 378

${ }^{22}$ Potosí. Departamento del SO. de Bolivia, limítrofe con Chile y Argentina; 118.218 km² y 949.000 hab. Forma parte del Altiplano y está accidentado por la cordillera Real en su mitad oriental. Cereales, patatas, legumbres y quina. Ganadería. Minas de plomo, estaño, plata. Salinas. Capital, Potosí. Enciclopedia Textual... op. cit.

${ }^{23}$ García Ramón. Op. cit. Pp. 296-297

${ }^{24}$ Me refiero a obras como El Fisiólogo. Bestiario Medieval. Prol. Juli Peradejordi. España, Ediciones Obelisco, 2000. (Colección Archivo de Símbolos). También: Ignacio Malaxecheverría. Bestiario Medieval. España, Ediciones Siruela, 1999 (Biblioteca Medieval Siruela) 
a la virtud o al pecado y de su virtud moralizante, y su nueva dimensión se construía en función de la utilidad que proporcionaba al hombre.

\section{Un curso de historia natural}

Impreso en la Librería de la viuda de Charles Bouret, París-México, el libro de J. Langlebert, profesor de ciencias físicas y naturales, doctor en Medicina y oficial de Academia, se anuncia como una obra «enteramente refundida, con arreglo a las clasificaciones Zoológica, Botánica y Geológica admitidas en las grandes escuelas francesas y europeas en 1899». Traducida por Don Antonio de Linares, la obra contiene 680 grabados en el texto, dos de ellos iluminados. Este ejemplar corresponde a la onceava edición española que incluye adiciones y reformas del autor en 1901.25 En la nota de la sesenta y tresava edición francesa, que es la que se traduce, Langlebert aclara que ha modificado su trabajo haciéndolo nuevo y enteramente acorde con los programas de enseñanza del momento. Si bien la clasificación zoológica no había exigido sino cambios de escasa importancia, por el contrario en la botánica se daba una descripción más moderna de la estructura de las raíces, de los tallos y de las hojas, así como de los carpelos, de los óvulos y de los frutos, cuya clasificación se había simplificado en extremo. La clasificación del reino vegetal se había realizado de acuerdo con Brongniart. ${ }^{26} \mathrm{El}$ libro se halla estructurado en tres partes principales, después de una Nociones Preliminares, se abarca la Zoología, la Botánica y la Geología y Paleontología. Se define a la Historia Natural como la ciencia que estudia todos los cuerpos brutos o vivos esparcidos sobre la superficie de la tierra o constitutivos de la masa terrestre. Establece que si bien la Física y la Química se ocupan también de tales cuerpos, los miran desde otros puntos de vista. Por su parte la Física inquiría sobre las propiedades generales de la materia y los grandes fenómenos a que deben su origen, la atracción universal, el calor, la electricidad, el magnetismo, la luz; mientras la Química mide las fuerzas moleculares, indaga las leyes que presiden a las combinaciones y examina los productos nuevos que de ellas resulten. La Historia Natural a su vez investiga el origen, el modo en que los cuerpos crecen y se constituyen, sus formas exteriores, su organización o estructura interna, su distribución geográfica, en suma todos los caracteres que pueden servir para distinguirse entre sí. ${ }^{27}$ Los tres reinos admitidos por la ciencia y el lenguaje usual a los que se referirá Langlebert son el mineral, que comprende los cuerpos brutos o inorgánicos; el animal y el vegetal, donde están reunidos todos los seres dotados de vida. Así los caracteres distintivos de los cuerpos inorgánicos y de los seres organizados son: origen, duración, desarrollo, nutrición y organización, precisándose la celular para lo viviente. ${ }^{28}$ La especie, Langlebert explica,

\footnotetext{
${ }^{25}$ J. Langlebert. Historia Natural. Curso elemental de estudios científicos. Trad. por D. A. de Linares. Librería de la Vda. de Ch. Bouret. París/México, 1901.

${ }^{26}$ Brongniart, Alexandre (1770-1847). Geólogo francés. Colaborador de Cuvier, estableció la primera ordenación cronológica de las formaciones geológicas del período terciario. Enciclopedia Textual... Op. cit.

${ }^{27}$ Langlebert. Op. cit., p. 1

28 Ibidem., p. 2
} 
viene de la voz latina species que significa en Historia Natural una colección de individuos dotados de caracteres comunes entre sí, y los distinguen de todos los demás individuos que pertenecen a otras especies. La reunión de muchas especies análogas constituyen un género. ${ }^{29} \mathrm{Y}$ cita a Cuvier, «La especie... es la reunión de individuos engendrados unos por otros, o por ascendientes comunes, y de cuantos se les parecen tanto como ellos en sí». ${ }^{30} \mathrm{El}$ autor reconoce que el origen de las especies animales y vegetales era una discusión para los naturalistas. Unos, como Linneo, ${ }^{31}$ Jussieu $^{32}$ y Cuvier, consideraban la especie como un tipo fijo, invariable, que había conservado a través de las generaciones desde su origen su forma primitiva y esencial. Pero otros, como Lamarck, Geoffroy Saint-Hilaire y el naturalista inglés Carlos Darwin pretendían, al contrario, que las especies, lejos de ser fijas e inmutables, con el tiempo y bajo el influjo de causas diversas pueden modificarse poco a poco y transformarse en nuevos tipos específicos de un orden superior. Estas a su vez en el curso del tiempo y por causas activas podrían producir otras especies y así sucesivamente. ${ }^{33}$ Pero en lo que a materia de clasificación se refería consideraba como las más célebres a las de Linneo, Lamarck ${ }^{34}$ y Jorge Cuvier. Linneo había dividido a los mamíferos, las aves, los reptiles, los peces, los insectos y los gusanos. Lamarck en 1801 dividió a los ani-

\footnotetext{
29 Ibidem., p. 5

${ }^{30}$ Ibidem., p. 6
}

${ }^{31}$ Linné, Carl von (1707-1778). Naturalista sueco, conocido también con el nombre castellanizado de Linneo. Se le considera el padre de la botánica moderna. Desde edad temprana mostró gran afición a la botánica. Entró en la Universidad de Lund, donde inició los estudios de medicina, y al cabo de un año pasó a la de Uppsala. Habiendo adquirido cierta reputación por sus trabajos de botánica, la Real Sociedad de Ciencias de esta última ciudad le subvencionó un viaje a través de Laponia, cuyo resultado fue materia del libro Flora lapponica, publicado en 1737. Este mismo año pasó a la Universidad de Hardewijck en Holanda, donde se graduó de doctor en medicina. Estuvo luego en Leiden, donde aparecieron los primeros ensayos de su Systema naturae y Fundamenta botanica. Más tarde se estableció en Estocolmo para ejercer la medicina. En 1741 fue nombrado catedrático de medicina en Uppsala y luego de botánica e historia natural. Linné fue ante todo un gran sistemático; ideó la nomenclatura binaria, pronto aceptada universalmente, con lo que puso orden en el caos taxonómico imperante hasta entonces. La primera edición de su obra Species plantarum (1753) ha sido aceptada internacionalmente como el punto de partida para la nomenclatura botánica actual. Del mismo modo, su Systema naturae (1735-58) constituye la base de la taxonomía zoológica. Clasificó las plantas basándose en los caracteres sexuales, e intentó establecer una sistemática natural de los seres vivientes. Además de las obras ya citadas, deben señalarse también: Genera plantarum (1737), Classes plantarum (1738), Flora suecica (1745), Fauna suecica (1745) y Philosophia botanica (1751). Enciclopedia Textual... Op. cit.

32 Jussieu, Bernard de (1699-1777). Botánico francés. Fundó un método de clasificación de las plantas basado en los caracteres anatómicos del embrión. Desarrollado por su sobrino, Antoine-Laurent de Jussieu, se convirtió en la primera clasificación natural de los vegetales. Enciclopedia Textual... Op.cit.

33 Langlebert. Op. cit., pp. 6 y 7

${ }^{34}$ Lamarck, Jean-Baptiste de Monet de (1744-1829). Naturalista francés. Empezó dedicándose a la botánica e ideó el sistema de claves dicotómicas que aplicó a los vegetales. En 1792 fue nombrado profesor del Jardin des Plantes (instituto de biología general) y se dedicó a la zoología, a la que prestó múltiples servicios: estudió intensamente los invertebrados, que separó por completo de los vertebrados; se aproximó a la teoría celular, que formularon 39 años después Schleiden y Schwann. Los estudios sistemáticos le llevaron a formular su teoría de la evolución, que expuso en Philosophie zoologique (1809), donde afirmó que las especies no son constantes, sino que derivan de especies preexistentes. Enciclopedia Textual... Op. cit. 
males en dos grandes series: vertebrados, con esqueleto interno, e invertebrados, sin él. Jorge Cuvier en 1820 había construido la clasificación mayormente seguida hasta entonces por los naturalistas. A cada grupo correspondía una modificación particular en la estructura y la conformación del sistema nerviosos y constuían las cuatro grandes divisiones primarias del reino animal que Cuvier denominó ramas: los vertebrados, los articulados, los moluscos, los radiados o zoofitos. ${ }^{35}$

En suma, nuevos lenguajes y valoraciones de la naturaleza desde una ciencia moderna que se expandía en territorios académicos a través de redes aparentemente intangibles.

\footnotetext{
${ }^{35}$ Langlebert. Op. cit., p. 199
} 
(Página deixada propositadamente em branco) 


\section{Colecçãa \\ 2 Ciências e Culturas Caimbra 2006}

